\title{
Summer distribution and abundance of juvenile Chinese horseshoe crabs Tachypleus tridentatus along an intertidal zone in southern China
}

\author{
Menghong Hu ${ }^{1}$, Youji Wang ${ }^{1}$, Yan Chen ${ }^{1}$, Siu-Gin Cheung ${ }^{1}$, Paul K. S. Shin ${ }^{1, *}$, \\ Qiongzhen $\mathbf{L i}^{2}$
}

\author{
${ }^{1}$ Department of Biology and Chemistry, City University of Hong Kong, Tat Chee Avenue, Kowloon, Hong Kong, SAR \\ ${ }^{2}$ Guangxi Institute of Fisheries, Nanning, Guangxi, 530021, PR China
}

\begin{abstract}
Owing to human exploitation, pollution and loss of breeding and nursery grounds, Chinese horseshoe crabs Tachypleus tridentatus are facing the risk of population decline and eventual extinction. In order to provide baseline information needed to formulate future conservation strategies, we examined the spatial distribution, densities and carapace width of juvenile T. tridentatus along 6 transects at an intertidal zone of Beibu Gulf, South China Sea, during the summer of 2008. The environmental parameters measured (water temperature, salinity and dissolved oxygen) did not vary significantly among transects. However, the abundance and size distribution of juvenile T. tridentatus was statistically different between transects. Juvenile $T$. tridentatus prefer to move further from their natal area as they grow: therefore, smaller juveniles tend to be distributed closer to the shore, while larger juveniles are located further offshore.
\end{abstract}

KEY WORDS: Chinese horseshoe crab · Tachypleus tridentatus · Distribution · Abundance · Size variation · Intertidal zone $\cdot$ Beibu Gulf

\section{INTRODUCTION}

Horseshoe crab is the common name of 4 species of marine arthropods (Xiphosura, Chelicerata) found on the east coasts of Asia and North America. Despite their name, these animals are not crabs at all, but are related to scorpions, spiders and extinct trilobites. Tachypleus tridentatus (Leach 1819), known as the Japanese or Chinese horseshoe crab, is a species in the family Tachypleinae.

Tachypleus tridentatus larvae tend to stay in their nests immediately after hatching, where they usually reside over winter. They then leave the nests and live at or near their natal beaches throughout the next spring or summer (Sekiguchi 1988). Juvenile T. tridentatus bury themselves in the sand/mud sediment during high tide and emerge on the sediment surface to feed during low tide (Chen et al. 2004, Chiu \& Morton 2004); therefore, they can be found at the sediment surface or buried in sediments in their nursery intertidal zone (Rudloe 1979). Adult T. tridentatus spend the winter in hibernation on the offshore ocean bottom at depths of $20 \mathrm{~m}$, and then migrate from their winter deeper-water habitat to the shallow areas of coves when seawater temperatures rise in the summer (Sekiguchi 1988). The life-history characteristics and habitat preferences of the Chinese horseshoe crab suggest that the dispersal capability of juveniles might be restricted, resulting in substantial population subdivisions on a small geographic scale (Pierce et al. 2000, King et al. 2005).

Populations of Tachypleus tridentatus in Asia have declined sharply for the past several decades. In Japan, T. tridentatus has been designated as a protected species since 1928 owing to near extinction, but its population size remains under threat (Botton et al. 1996). Hong Kong populations have shown similar trends, with declines in juvenile densities found on nursery beaches in 
recent years (Morton 1999, Chiu \& Morton 2003a, Shin et al. 2009). In Taiwan, the status of $T$. tridentatus is even worse than that in Japan and Hong Kong; horseshoe crabs were formerly abundant along the coastal zone of Taiwan, but are now rarely found on inshore mudflats (Chen et al. 2004). Besides habitat destruction and marine pollution, overharvesting for food or biomedical production of Tachypleus amebocyte lysate (TAL) is the main reason for the decrease of T. tridentatus in South China, Malaysia, Vietnam and other areas in the region (Itow 1993, Chen et al. 2004). Surveys of the distribution and abundance of $T$. tridentatus are therefore necessary, because they can provide firsthand data for the government to establish feasible protective measures for this important marine animal.

As a poikilotherm (Fraenkel 1960), juvenile horseshoe crabs, which prefer living in the intertidal, are greatly influenced by thermal stress, particularly under local extreme temperatures in the hot summer and cold winter. They become inactive, bury into deep sediments or even undergo diapause in winter (Morton \& Lee 2003). Sekiguchi (1988) regarded this low winter activity of horseshoe crabs as its hibernation. Chiu \& Morton (2004) also found that juvenile Tachypleus tridentatus effectively disappear from the beach and go into hibernation in winter, and start to feed again the following spring (March/April). These studies indicated that summer is the best season to conduct distribution and abundance surveys of juvenile horseshoe crabs, because it is easy to find them during low tide due to their feeding behaviour.

There is little published information on Chinese horseshoe crabs in the South China Sea, except from studies in areas such as Hong Kong (Chiu \& Morton 1999, 2003a, Shin et al. 2009) and Taiwan (Chen et al. 2004). The spatial distribution and abundance of Tachypleus tridentatus along the China mainland coast has not been well defined. The South China Sea is one of the main habitats for T. tridentatus; however, apart from its existence, there is no information on its distribution and abundance. For example, mating pairs of $T$. tridentatus have been found along the Beibu Gulf in South China Sea (from anecdotal records). Therefore, the intertidal zone along Beibu Gulf is considered to be an important nursery ground for juvenile $T$. tridentatus. However, no quantitative data on the population density of juvenile $T$. tridentatus are available from the literature.

In the present study, an intensive survey on the spatial distribution, abundance and size distribution of juvenile Tachypleus tridentatus was undertaken along the intertidal zone of Beibu Gulf in Beihai, Guangxi Province of China, in order to determine whether or not a large population of juveniles exists. We chose this intertidal zone because the area supports a signif- icant population of actively spawning adult horseshoe crabs and furnishes substantial feeding and nursery grounds, based on preliminary survey data from earlier studies by the Guangxi Institute of Fisheries. Although it is impossible to reach any valid conclusion on changes in the population of juvenile $T$. tridentatus in recent years at the study area owing to the lack of welldefined baseline data, we constructed the first, to our knowledge, description of the juvenile $T$. tridentatus population in the study area. Results from the present study will illustrate the current population status of juvenile horseshoe crabs in part of the South China Sea, data which are critical for subsequent studies on the ecology and biology of $T$. tridentatus in China.

\section{MATERIALS AND METHODS}

Study site. Beibu Gulf is a semi-enclosed sea which is located at $17^{\circ} 00^{\prime}$ to $21^{\circ} 45^{\prime} \mathrm{N}$ and $105^{\circ} 40^{\prime}$ to $110^{\circ} 10^{\prime} \mathrm{E}$ and is surrounded by China, Vietnam and China's Hainan Island (Fig. 1). Its total area is about $128000 \mathrm{~km}^{2}$. Several rivers flow into the Gulf, including the Red, Fangcheng, Nanliujiang, Qinjiang, Dafengjiang, Beilunhe, Fengjiajiang and Changhuajiang Rivers, bringing various nutrients to the Gulf from the land and re-

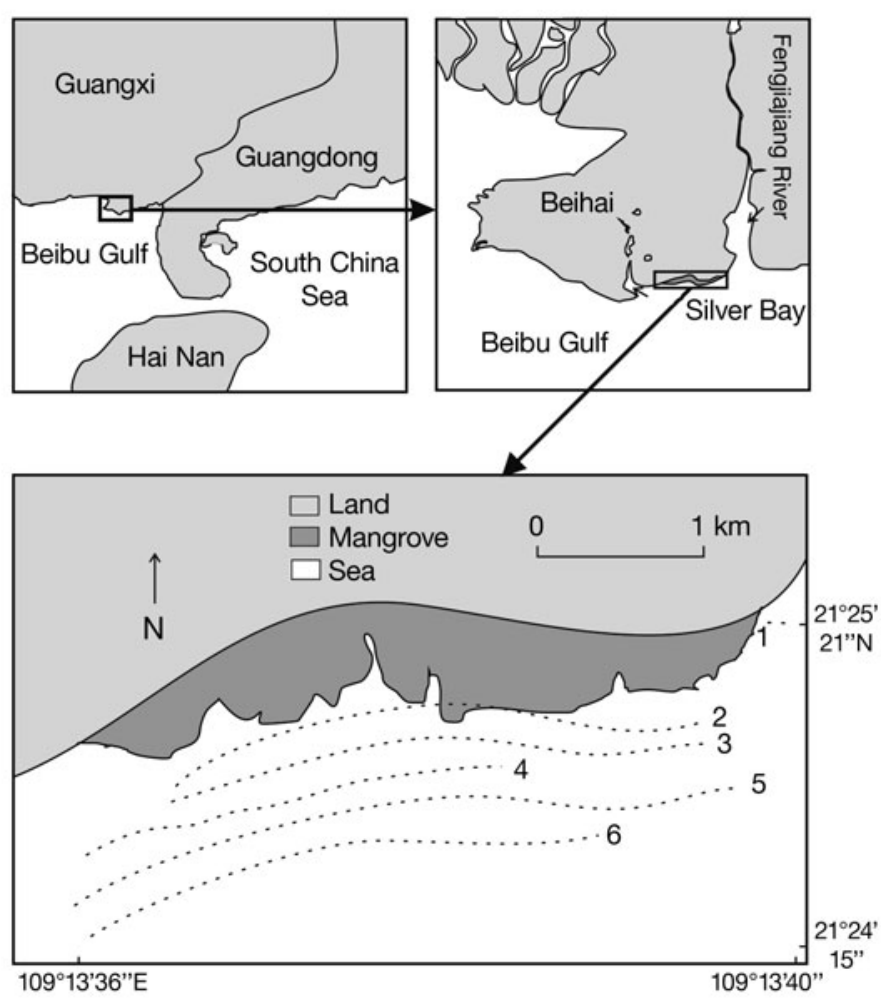

Fig. 1. Location of the study area. Dashed lines represent transect lines. Note that Transect 1 is very short, between the mangrove zone and open sea 
Table 1. Characteristics and environmental parameters (mean values) of the 6 sampling transects

\begin{tabular}{|c|c|c|c|c|c|c|c|}
\hline Transect & Latitude & Longitude & $\begin{array}{l}\text { Distance from } \\
\text { coastline } \\
\text { (m) }\end{array}$ & Description & $\begin{array}{c}\text { Temperature } \\
\left({ }^{\circ} \mathrm{C}\right)\end{array}$ & $\begin{array}{l}\text { Salinity } \\
\qquad \% \text { ) }\end{array}$ & $\begin{array}{c}\text { Dissolved } \\
\text { oxygen } \\
\left(\mathrm{mg} \mathrm{l}^{-1}\right)\end{array}$ \\
\hline 1 & $21^{\circ} 25^{\prime} 21^{\prime \prime} \mathrm{N}$ & $109^{\circ} 13^{\prime} 36^{\prime \prime}-109^{\circ} 13^{\prime} 40^{\prime \prime} \mathrm{E}$ & - & Upper estuary & 32.13 & 27.63 & 8.19 \\
\hline 2 & $21^{\circ} 25^{\prime} 12^{\prime \prime}-21^{\circ} 25^{\prime} 19^{\prime \prime} \mathrm{N}$ & $109^{\circ} 11^{\prime} 10^{\prime \prime}-109^{\circ} 13^{\prime} 36^{\prime \prime} \mathrm{E}$ & 750 & Mangrove zone edge & 30.20 & 29.35 & 8.33 \\
\hline 3 & $21^{\circ} 25^{\prime} 01^{\prime \prime}-21^{\circ} 25^{\prime} 07^{\prime \prime} \mathrm{N}$ & $109^{\circ} 11^{\prime} 02^{\prime \prime}-109^{\circ} 13^{\prime} 36^{\prime \prime} \mathrm{E}$ & 1000 & Open shore & 31.15 & 30.09 & 8.15 \\
\hline 4 & $21^{\circ} 24^{\prime} 52^{\prime \prime}-21^{\circ} 24^{\prime} 58^{\prime \prime} \mathrm{N}$ & $109^{\circ} 10^{\prime} 44^{\prime \prime}-109^{\circ} 12^{\prime} 52^{\prime \prime} \mathrm{E}$ & 1250 & Open shore & 31.20 & 30.07 & 8.20 \\
\hline 5 & $21^{\circ} 24^{\prime} 52^{\prime \prime}-21^{\circ} 25^{\prime} 17^{\prime \prime} \mathrm{N}$ & $109^{\circ} 11^{\prime} 18^{\prime \prime}-109^{\circ} 13^{\prime} 26^{\prime \prime} \mathrm{E}$ & 1500 & Open shore & 31.21 & 30.05 & 8.14 \\
\hline 6 & $21^{\circ} 24^{\prime} 15^{\prime \prime}-21^{\circ} 24^{\prime} 45^{\prime \prime} \mathrm{N}$ & $109^{\circ} 10^{\prime} 36^{\prime \prime}-109^{\circ} 12^{\prime} 54^{\prime \prime} \mathrm{E}$ & 1750 & Open shore & 31.20 & 30.16 & 8.18 \\
\hline
\end{tabular}

sulting in an extensive estuarine ecosystem (Zhao 1999). The annual average water temperature is about $24^{\circ} \mathrm{C}$ (minimum $=2{ }^{\circ} \mathrm{C}$; maximum $=37.1^{\circ} \mathrm{C}$ ). The intertidal zone used in the present study is located within the Beihai Mangrove Reserve, the largest mangrove reserve habitat in southeast China.

Sample measurement. The survey method was based on Chiu \& Morton (2003b) and was similar to Carmichael et al. (2003). From 7 to 16 August 2008, 6 transects (10 m width) were set, equally spaced (at $250 \mathrm{~m}$ ) and parallel to the coastline, from the sublittoral zone to a tidal level of $0.7 \mathrm{~m}$ above chart datum. The length of each transect was determined by the geomorphological characteristics of the intertidal zone. All transects were located in sediments intermediate between mud and sand.

Purse nets, which were set up by local fishermen, divided the sampling area of each transect into discrete sampling units. The area of each sampling unit varied depending on the area enclosed by the purse nets. Within each sampling unit, 1 quadrat $(10 \times$ $10 \mathrm{~m}$ ) was randomly placed for abundance counts and size measurement of juvenile Tachypleus tridentatus. The number of horseshoe crabs found on the sediment surface within each quadrat was recorded and the carapace width (maximum prosomal width) was measured using vernier calipers.

Environmental parameters within each quadrat, including temperature, salinity and dissolved oxygen of the interstitial waters, were monitored using a glass thermometer, a hand-held refractometer (Model ATAGO S/Mill-E) and an oxygen electrode (YSI Model 58), respectively. The environmental characteristics of each transect are described in Table 1.

Statistical analysis. Results of density and juvenile carapace width measurements are presented as means \pm SE. As the population density and size distribution of juvenile Tachypleus tridentatus was not normally distributed, differences among transects were examined using the non-parametric Kruskal-Wallis (KW) test. If significant differences were found, a nonparametric Mann-Whitney multiple comparison test was computed. The significance level for both KW and Mann-Whitney $U$-tests was set at $\mathrm{p}<0.05$. All statistical analyses were undertaken using the software SPSS 16.0 for Windows.

\section{RESULTS}

\section{Distribution and abundance}

Table 2 shows the density of juvenile Tachypleus tridentatus recorded in each transect. Mean density ranged from 0.09 individuals $100 \mathrm{~m}^{-2}$ (Transect 6) to 2.43 individuals $100 \mathrm{~m}^{-2}$ (Transect 3 ). There was a significant difference (KW test, $H=25.311, \mathrm{p}=0$ ) in the density distribution of juveniles between transects: densities of juveniles in Transect 3, 4 and 5 were significantly higher than in Transect 6 .

Table 2. Tachypleus tridentatus. Total number, density and carapace width of juvenile T. tridentatus found in the 6 transects. Density values are mean \pm SE of total sampling area; carapace width values are mean $\pm \mathrm{SE}$ of the number of $T$. tridentatus in each transect. Values with different superscripts in a column denote significant differences $(\mathrm{p}<0.05)$

\begin{tabular}{|c|c|c|c|c|c|c|c|}
\hline \multirow[t]{2}{*}{ Transect } & \multirow{2}{*}{$\begin{array}{c}\text { No. sampling } \\
\text { units }\end{array}$} & \multirow{2}{*}{$\begin{array}{c}\text { Sampling } \\
\text { area }\left(100 \mathrm{~m}^{2}\right)\end{array}$} & \multirow{2}{*}{$\begin{array}{l}\text { No. of } \\
\text { ind. }\end{array}$} & \multirow{2}{*}{$\begin{array}{c}\text { Density } \\
\text { (ind. } 100 \mathrm{~m}^{-2} \text { ) }\end{array}$} & \multicolumn{3}{|c|}{ Carapace width $(\mathrm{mm})$} \\
\hline & & & & & Mean & Min. & Max. \\
\hline 1 & 3 & 11.6 & 7 & $0.60 \pm 0.45^{\mathrm{abc}}$ & $34.4 \pm 4.8^{\mathrm{ab}}$ & 13.4 & 56.8 \\
\hline 2 & 6 & 110 & 24 & $0.22 \pm 0.02^{\mathrm{ac}}$ & $37.3 \pm 3.3^{\mathrm{a}}$ & 17.8 & 76.9 \\
\hline 3 & 36 & 398.1 & 966 & $2.43 \pm 0.13^{\mathrm{a}}$ & $31.2 \pm 0.3^{\mathrm{ac}}$ & 8.3 & 100.2 \\
\hline 4 & 83 & 351.7 & 360 & $1.02 \pm 0.03^{\mathrm{ab}}$ & $32.9 \pm 0.5^{\mathrm{ab}}$ & 8.0 & 99.2 \\
\hline 5 & 39 & 346.3 & 416 & $1.20 \pm 0.04^{\mathrm{ab}}$ & $34.3 \pm 0.7^{a}$ & 8.8 & 124.8 \\
\hline 6 & 30 & 570 & 51 & $0.09 \pm 0.01^{\mathrm{c}}$ & $34.1 \pm 3.3^{\mathrm{a}}$ & 9.2 & 85.8 \\
\hline
\end{tabular}




\section{Spatial variations in size}

A total of 1824 horseshoe crabs were recorded by the transect sampling method. Results of the size range data are presented in Table 2. The carapace width of juvenile Tachypleus tridentatus in Transect 4 was significantly lower than that in Transects 2 and 6. The maximum carapace width $(125 \mathrm{~mm})$ was recorded in juveniles found in Transect 5, while the minimum carapace width $(8 \mathrm{~mm})$ was recorded in juveniles sampled in Transects 3 and 4 . Juvenile T. tridentatus in Transect 2 had the highest average carapace width of $37.25 \mathrm{~mm}$, whereas those in Transect 3 had the lowest average carapace width of $31.16 \mathrm{~mm}$. There was a significant difference (KW test, $H=13.632, \mathrm{p}=0.018$ ) in the size distribution of juveniles between transects: juveniles in Transect 3 were significantly smaller than those in Transects 1 and 4 . Fig. 2 shows the size-frequency distribution of juveniles in each transect. Juveniles between 29 and $39 \mathrm{~mm}$ carapace width comprised the majority of individuals in Transects 1, 3, 4 and 5, while juveniles between 9 and $19 \mathrm{~mm}$ carapace width were in the majority in Transect 6.

\section{DISCUSSION}

\section{Distribution and abundance}

In the present study, an intensive population distribution investigation of juvenile Tachypleus tridentatus was conducted along 6 horizontal transects in the intertidal zone of Beibu Gulf, from the edge of the mangrove zone down to the open sea area, with similar sampling strategies as in the previous distribution study by Morton \& Lee (2003). The total survey area in the intertidal zone was $178768 \mathrm{~m}^{2}$. Based on the distribution data obtained, juvenile $T$. tridentatus were not evenly distributed throughout the study area. The average density of juvenile $T$. tridentatus in the survey area was 1.02 individuals $100 \mathrm{~m}^{-2}$; the highest average density occurred in Transect 3 (2.43 individuals $100 \mathrm{~m}^{-2}$; total area $=39810 \mathrm{~m}^{2}$ ).

In the Philippines, population studies on juvenile Tachypleus tridentatus conducted on 2 shores in Palawan in 2001 and 2002 (Kaiser 2002, Almendral \& Schoppe 2005) obtained average densities of 2.00 and 1.47 individuals $100 \mathrm{~m}^{-2}$, respectively. Intensive population distribution and abundance studies of juvenile T. tridentatus have also been conducted in Hong Kong (Morton \& Lee 2003, Li 2008). Morton \& Lee (2003) found densities of $0.10,1.97,1.55$ and 1.14 individuals $100 \mathrm{~m}^{-2}$ at 4 beaches, while Li (2008) reported a sharp decline in density at 17 beaches from 2002 to 2004; juvenile $T$. tridentatus densities decreased from $1.1-2.0$ to $0-0.3$ individuals per $100 \mathrm{~m}^{2}$.

Li (2008) indicated that a higher abundance of juvenile horseshoe crabs was obtained in the summer when the air temperature averaged $22.2^{\circ} \mathrm{C}$, and found peak Tachypleus tridentatus abundances in most of the summer (May to August). This observation was further confirmed by a laboratory experiment on the effect of temperature on the behaviour of horseshoe crabs, in which they tended to become inactive at $9^{\circ} \mathrm{C}$, compared to water temperatures of 19,29 and $39^{\circ} \mathrm{C}$ (H. Y. Li unpubl. data). MacIntosh (1989) found that the distribution of fiddler crabs on sandy shores was related to many environmental factors, coinciding with Frusher et al. (1994), who indicated that salinity and substratum characteristics are the most important

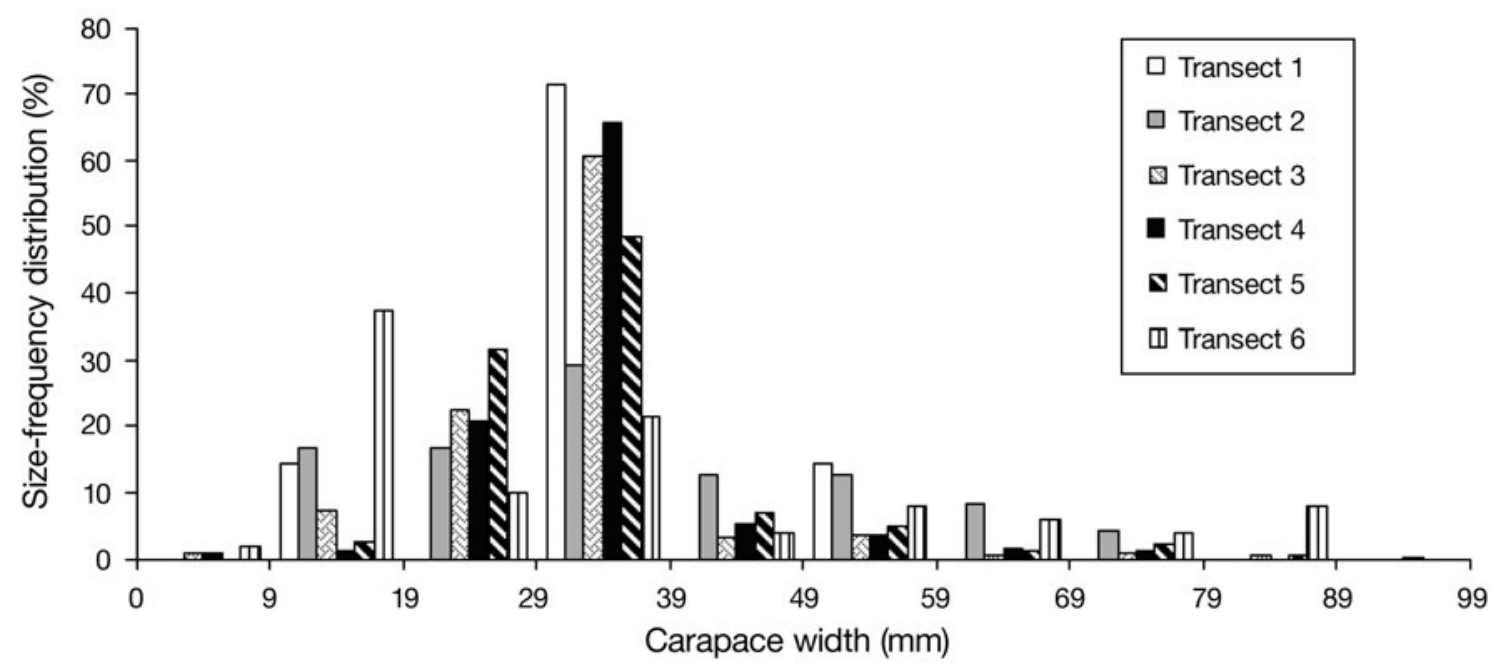

Fig. 2. Tachypleus tridentatus. Juvenile T. tridentatus size-frequency distribution by transect 
factors that can influence the spatial distribution of a great number of crustacean decapods. One such characteristic is sediment grain size (Bezerra et al. 2006).

Similar associations were recorded by Li (2008), who indicated sediment grain size was the main factor affecting the spatial distribution of 2 horseshoe crab species. According to Li (2008), juvenile Tachypleus tridentatus prefer living in shaded areas composed of fine sand, while juvenile Carcinoscorpius rotundicauda show a higher affinity for muddy sediments. In the present study, water temperature, salinity and dissolved oxygen values showed no significant differences among the 6 transects. Therefore, these environmental factors do not seem to be the determining factors for the distribution of juvenile T. tridentatus in the intertidal zone.

Newly hatched juvenile horseshoe crabs do not need to feed, because they can subsist on the yolk of the embryos for several months (Botton et al. 1992); only 2nd instars have to feed (Sekiguchi 1988). Therefore, in the wild, it is difficult to locate juveniles younger than 2nd instar stage because they do not leave any feeding traces on the sediment surface.

The density distribution of juvenile Tachypleus tridentatus did not appear strongly related to distance from the coastline, although we cannot be sure that distance does not affect settlement or early life history because we were unable to sample very small $T$. tridentatus.

\section{Size distribution}

Juveniles of variable size, ranging between 8 and $125 \mathrm{~mm}$ in carapace width and representing different ages, were observed in all 6 transects. According to the size-age relationships established by Sekiguchi (1988), the age of juvenile Tachypleus tridentatus sampled in present study ranged from 1 to $12 \mathrm{yr}$ old. This finding implies that the study area may be an important local nursery ground for juvenile T. tridentatus.

It is generally believed that horseshoe crab eggs are laid on the upper shore. Thus the juveniles inhabit the intertidal areas and then move further offshore with increasing age (Shuster 1979, Sekiguchi 1988). In Chiu \& Morton (2004), older and larger juveniles of Tachypleus tridentatus were found farther offshore than younger juveniles in Hong Kong, and this phenomenon was also observed in L. polyhemus in Florida (Rudloe 1981). The results of the present study, however, were not consistent with these findings. Factors other than distance from the coastline may have contributed to the disagreement between our results and those reported by previous studies. For example, differences in food distribution among transects might affect the density and size variations among different transects. However, we have not evaluated this factor in the present study. In the present study, significant spatial variations in the size of juvenile T. tridentatus in different transects were detected. Older cohorts (carapace width $=29$ to $39 \mathrm{~mm}, 4$ to $6 \mathrm{yr}$ old), were in the majority in some transects (Transects 1, 3, 4 and 5), while younger cohorts (carapace width $=19$ to $29 \mathrm{~mm}$, 3 to 5 yr old) were in the majority only in Transect 6 , which was located further offshore. Our findings suggest that it might be erroneous to age horseshoe crabs simply from the size-age relationship of Sekiguchi (1988), since environmental characteristics can affect growth performance (Jegla \& Costlow 1982). For example, the American horseshoe crab Limulus polyphemus living in salinities of $<18 \%$ o was significantly smaller than those living at higher salinities (Shuster 1950).

In conclusion, the results from the present study indicate that juvenile Tachylpeus tridentatus tend to be distributed in discrete patches. Both population abundance and spatial size distribution showed a nonlinear relationship with distance from the coastline. The size distribution of juveniles in each transect revealed that smaller juveniles tended to occur closer to the shore, while larger ones were generally located further offshore.

Acknowledgements. We thank staff from the Guangxi Institute of Fisheries, China, for assistance with the field work and the Ocean Park Conservation Fund of Hong Kong for providing financial support for this study. Special thanks also go to B. Morton and S. G. Hong for their advice on horseshoe crab ecology.

\section{LITERATURE CITED}

Almendral MA, Schoppe S (2005) Population structure of Tachypleus tridentatus (Chelicerata: Merostomata) at a nursery beach in Puerto Princesa City, Palawan, Philippines. J Nat Hist 39:2319-2329

Bezerra LEA, Dias CB, Santana GX, Matthews-Cascon H (2006) Spatial distribution of fiddler crabs (genus UCa) in a tropical mangrove of northeast Brazil. Sci Mar 70:759-766

Botton ML, Loveland RE, Jacobsen TR (1992) Overwintering by trilobite larvae of the horseshoe crab Limulus polyphemus on a sandy beach of Delaware Bay (New Jersey, USA). Mar Ecol Prog Ser 88:289-292

Botton ML, Shuster CN, Sekiguchi K, Sugita H (1996) Amplexus and mating behavior in the Japanese horseshoe crab, Tachypleus tridentatus. Zool Sci 13:151-159

Carmichael RH, Rutecki D, Valiela I (2003) Abundance and population structure of the Atlantic horseshoe crab Limulus polyphemus in Pleasant Bay, Cape Cod. Mar Ecol Prog Ser 246:225-239

Chen CP, Yeh HY, Lin PF (2004) Conservation of the horseshoe crab at Kinmen, Taiwan: strategies and practices. Biodivers Conserv 13:1889-1904

Chiu HMC, Morton B (1999) The distribution of horseshoe crabs in Hong Kong. In: Chiu HMC, Morton B (eds) The 
biology, distribution and status of horseshoe crabs, Tachyplues tridentatus and Carcinoscorpius rotundicauda (Arthropoda: Chelicerata) in Hong Kong: recommendations for conservation and management. Final Report to China Light and Power. Swire Institute of Marine Science, University of Hong Kong, Hong Kong, p 7-16

Chiu HMC, Morton B (2003a) The status of horseshoe crabs in Hong Kong. In: Morton B (ed) Proceedings of the Hong Kong workshops reunion conference on perspectives on marine environmental change in Hong Kong and Southern China (1977-2001). Hong Kong University Press, Hong Kong, p 743-758

Chiu HMC, Morton B (2003b) The morphological differentiation of two horseshoe crab species, Tachypleus tridentatus and Carcinoscorpius rotundicauda (Xiphosura), in Hong Kong with a regional Asian comparison. J Nat Hist 37: 2369-2382

Chiu HMC, Morton B (2004) The behaviour of juvenile horseshoe crabs, Tachypleus tridentatus (Xiphosura), on a nursery beach at Shui Hau Wan, Hong Kong. Hydrobiologia 523:29-35

Fraenkel G (1960) Lethal high temperatures for three marine invertebrates, Limulus polyphemus, Littorina littorea, and Pagurus longicarpus. Oikos 11:171-182

Frusher SD, Giddins RL, Smith TJ (1994) Distribution and abundance of grapsid crabs (Grapsidae) in a mangrove estuary: effects of sediment characteristics, salinity tolerances, and osmoregulatory ability. Estuaries 17:647-654

Itow T (1993) Crisis in the Seto Inland Sea: the decimation of the horseshoe crab. EMECS Newsl 3:10-11

Jegla TC, Costlow JD (1982) Temperature and salinity effects on developmental and early posthatch stages of Limulus. In: Bonaventura J, Bonaventura C, Tesh S (eds) Physiology and biology of horseshoe crabs: studies on normal and environmentally stressed animals. Alan R. Liss, New York, p 103-113

Kaiser D (2002) Zur Ökologie und Morphologie von Tachypleus tridentatus (Leach, 1819) (Chelicerata: Merostomata) im Gezeitenwatt der Ostküste von Palawan (Philippinen). MS thesis, University of Rostock

King TL, Eackles MS, Spidle AP, Brockmann HJ (2005) Regional differentiation and sex-biased dispersal among populations of the horseshoe crab Limulus polyphemus. Trans Am Fish Soc 134:441-465

Editorial responsibility: Matthias Seaman, Oldendorf/Luhe, Germany
Li HY (2008) The conservation of horseshoe crabs in Hong Kong. MPhil thesis, City University of Hong Kong, Hong Kong

MacIntosh DJ (1989) The ecology and physiology of decapods of mangrove swamps. Proc Zool Soc Lond 59:325-341

> Morton B (1999) On turtles, dolphins and, now, Asia's horseshoe crabs. Mar Pollut Bull 38:845-846

Morton B, Lee CNW (2003) Spatial and temporal distribution and abundance of juvenile horseshoe crabs along the northwestern shoreline of the New Territories. In: Morton B, Lee CNW (eds) The biology and ecology of juvenile horseshoe crabs along the northwestern coastline of the New Territories, Hong Kong: prospects and recommendations for conservation. Final Report to China Light and Power. Swire Institute of Marine Science, University of Hong Kong, Hong Kong, p 23-27

Pierce JC, Tan G, Gaffney PM (2000) Delaware Bay and Chesapeake Bay populations of the horseshoe crab Limulus polyphemus are genetically distinct. Estuaries 23: 690-698

Rudloe A (1979) Locomotor and light responses of larvae of the horseshoe crab, Limulus polyphemus (L). Biol Bull 157: 494-505

Rudloe A (1981) Aspects of the biology of juvenile horseshoe crabs, Limulus polyphemus. Bull Mar Sci 31:125-133

Sekiguchi K (1988) Biology of horseshoe crabs. Science House, Tokyo

Shin PKS, Li HY, Cheung SG (2009) Horseshoe crabs in Hong Kong: current population status and human exploitation. In: Tanacredi, JT, Botton ML, Smith DR (eds) Biology and conservation of horseshoe crabs. Springer, New York, p 347-360

Shuster CN (1950) Observations on the natural history of the American horseshoe crab, Limulus polyphemus. In: Shuster CN (ed) Third report on investigations of methods of improving the shellfish resources of Massachusetts. New Jersey Oyster Research Laboratory, New Jersey, p 18-23

Shuster CN (1979). Distribution of American horseshoe crab, Limulus polyphemus (L.). In: Cohen E (ed) Biomedical application of the horseshoe crab (Limulidae). Alan R. Liss, New York, p 3-26

Zhao HT (1999). The physiognomy and environment of the coasts in South China and islands in South China Sea. Science Press, Beijing, p 24-36

Submitted: March 27, 2009; Accepted: September 14, 2009

Proofs received from author(s): October 14, 2009 